\title{
Novel Identification of LYVE-1 Positive Macrophages in Rheumatoid Synovial Tissue
}

\author{
Lisa J. M. Rump1, Derek L. Mattey2,3, Oksana Kehoe',2, Jim Middleton 1,4 \\ ${ }^{1}$ Keele University, Arthritis Research Centre at the Robert Jones and Agnes Hunt Orthopaedic Hospital \\ Foundation Trust, Oswestry, UK \\ ${ }^{2}$ Institute for Science and Technology in Medicine, Medical School, Keele University, \\ Stoke-on-Trent, UK \\ ${ }^{3}$ Haywood Rheumatology Centre, Haywood Hospital, High Lane, Burslem, Stoke-on-Trent, UK \\ ${ }^{4}$ Faculty of Medicine and Dentistry, School of Oral and Dental Sciences, Bristol University, Bristol, UK \\ Email: ljmrump@gmail.com
}

Received 7 July 2016; accepted 14 August 2016; published 17 August 2016

Copyright (c) 2016 by authors and Scientific Research Publishing Inc.

This work is licensed under the Creative Commons Attribution International License (CC BY). http://creativecommons.org/licenses/by/4.0/

(c) ()

\section{Abstract}

Objective: LYVE-1+ macrophages are observed in a range of cancers, where they play a role in tumour lymphangiogenesis. In rheumatoid arthritis (RA), lymphangiogenesis increases in the early stage of the disease and decreases as it progresses, potentially exacerbating inflammatory cell persistence. We investigated whether LYVE-1+ macrophages were present in RA synovium. Methods: Synovial tissue from RA patients was obtained at joint replacement surgery and immunohistochemistry was performed to visualise LYVE-1+ and CD68+ cells. Results: LYVE-1+ macrophages were present in rheumatoid synovial tissue, the first observation of this kind. Conclusion: Despite the reduction in lymphangiogenesis in chronic RA, LYVE-1 positive macrophages are present and there is a potential role for macrophages in the generation of lymphatic vessels.

\section{Keywords}

LYVE-1, Macrophage, Rheumatoid Arthritis, Endothelial, Lymphatic

\section{Introduction}

The aim of the current study was to examine if macrophages expressing the lymphatic endothelial cell specific hyaluronan receptor LYVE-1 (LYVE-1 positive macrophages) existed in the RA synovium as their presence would indicate macrophage differentiation into lymphatic endothelial cell progenitors (LECPs) and the potential for further lymphatic vessel formation. It is accepted that macrophages are among a range of inflammatory cells 
which support the progression of metastatic cancers via angiogenesis and more recently the generation of new lymphatic vessels. Further to this, a number of studies have observed macrophages which are positive for LYVE-1 in cancers [1] with further evidence of activated macrophages as being LYVE-1 positive [2]. The LYVE-1+ status has previously been stated as indicating macrophage differentiation into macrophage-derived LECPs [2]. It has been shown that increases in the density of lymphatic vessels are associated with inflammatory diseases such as rheumatoid arthritis (RA) [3]. The accepted evidence reveals that lymphatic vessels form in response to disease states primarily by sprouting from existing lymphatic vessels (lymphangiogenesis), or via lymphvasculogenesis, the formation of vessels from lymphatic progenitor cells [2]. It has been shown that lymphatic vessel formation increases in early RA [4] and should act as a compensatory mechanism for the removal of the interstitial fluid containing the invading lymphocytes and pro-inflammatory chemokines and cytokines [5]. However, it has also been shown that despite an increase in lymphatic flow during the acute phase of arthritic inflammation, there is a decrease in lymphatic flow as new lymphatic vessels form during the chronic phase [6]. This had also been seen in the human TNF transgenic mouse (hTNFtf) model where lymphatic vessels increased in number through the initial stages of inflammation but underwent no further significant increases as synovitis progressed [7]. This would lead to reduction in removal of the ever increasing joint interstitial fluid. This is further exacerbated by the reduction in muscular contractions around the damaged joint that would normally encourage flow through the lymph vessels.

\section{Materials and Methods}

\subsection{Ethics}

Ethical approval was obtained from the Birmingham and Solihull Research Ethics Committee (reference 11/ $\mathrm{WM} / 0035$ ) and patients provided written informed consent.

\subsection{Synovial Tissue Samples}

RA synovial tissue was obtained from patients who were undergoing joint replacement surgery and fulfilled the American College of Rheumatology (ACR) criteria for RA $(n=8)$. Patients had the mean age of 66 years and a mean disease duration of 23 years at the time of surgery and were in the chronic stage of disease (Table 1). Non-RA control tissue from knee joints $(n=6)$ was obtained by needle biopsy during outpatient exploratory procedures where arthritis had been excluded as a diagnosis (Table 2).

RA tissue samples were taken from the suprapatellar pouch and the medial gutter of the knee and placed in Hank's Balanced Salt Solution (HBSS) for transport to the laboratory. All tissue samples were snap frozen in iso-pentane (cooled in liquid nitrogen) and then stored in liquid nitrogen. 5 - $6 \mu \mathrm{m}$ thick serial cryostat sections of the tissue were cut then dried at room temperature before being stored at $-80^{\circ} \mathrm{C}$.

Table 1. This table shows details of the RA tissue samples used.

\begin{tabular}{|c|c|c|c|c|c|}
\hline Patient & Sex & Age & $\begin{array}{l}\text { Age } \\
\text { at onset }\end{array}$ & $\begin{array}{l}\text { Disease } \\
\text { duration }\end{array}$ & Medictaion \\
\hline RA1 & $\mathrm{F}$ & 77 & 62 & 16 & $\begin{array}{l}\text { Piroxicam, Paracetamol, Omeprazole, Diclofenac, } \\
\text { Methylprednisolone } 40 \mathrm{mg} \text {, Methotrexate } 10 \mathrm{mg}\end{array}$ \\
\hline RA2 & $\mathrm{F}$ & 48 & 33 & 15 & Diclofenac \\
\hline RA3 & M & 77 & 62 & 16 & Sulphasalazine, Methotrexate, Gold, Chloroquine \\
\hline RA4 & $\mathrm{F}$ & 48 & 33 & 15 & $\begin{array}{c}\text { Leflunomide 10mg, Co-codamol, Omeprazole, } \\
\text { Naproxen prednisolone } 5 \text { mg, Lisinopril (Enalopril), } \\
\text { Actonel (Risedronate), Calcichew D3 (calcium plus vitamin D) }\end{array}$ \\
\hline RA5 & $\mathrm{F}$ & 72 & $\mathrm{~N} / \mathrm{A}$ & $>23$ & N/A \\
\hline RA6 & $\mathrm{F}$ & 61 & 41 & 20 & Sulphasalazine, Azathioprine, Methotrexate, Gold \\
\hline RA7 & $\mathrm{F}$ & 83 & 48 & 35 & Sulphasalazine, Oruvail (ketoprofen), Co-codamol, Dihydrocodeine \\
\hline RA8 & $\mathrm{F}$ & 74 & 39 & 35 & Didronel (Etidronate), Methotrexate 2.5 mg, Prednisolone 5 mg, Co-dydramol \\
\hline
\end{tabular}


Table 2. This table shows details of the non-RA samples used.

\begin{tabular}{cccc}
\hline Patient & Sex & Age & Diagnosis \\
Non RA1 & F & 47 & Tear to lateral meniscus \\
Non RA2 & M & 41 & Patella tendon decompression \\
Non RA3 & F & 45 & Probable tear to lateral meniscus \\
Non RA4 & M & 45 & Probable tear to right medial meniscus \\
Non RA5 & F & 41 & Thickened medial plica, rest of meniscus normal \\
Non RA6 & M & 41 & Partial medial meniscectomy. Rest of meniscus normal \\
\hline
\end{tabular}

\subsection{Double Immunofluorescent Labelling of Tissues}

Sections were stained as previously described [8]. Briefly, sections were blocked for 30 minutes with 10\% donkey serum (Invitrogen, Paisley, UK) and 0.3\% triton-X in phosphate buffered saline (PBS) (both Invitrogen) and were then washed for 5 minutes in PBS. Following this, the sections were incubated for 1 hour at room temperature with the primary goat anti-human LYVE-1 antibody, $2 \mu \mathrm{g} / \mathrm{mL}$ (R \& D Systems, Oxfordshire, UK) and mouse anti-human CD68 (2 $\mu \mathrm{g} / \mathrm{mL})$ (Dako, Cambridgeshire, UK) in the dilution buffer consisting of $1 \%$ donkey serum and $0.3 \%$ triton X in PBS (all Invitrogen). Following incubation sections were washed three times for five minutes in PBS. The secondary antibody solution of donkey anti-goat alexafluor 594 at $6.6 \mu \mathrm{g} / \mathrm{mL}$ or donkey anti-mouse alexafluor 594 IgG at $6.6 \mu \mathrm{g} / \mathrm{mL}$ and donkey anti-goat alexafluor 488 at $3.3 \mu \mathrm{g} / \mathrm{mL}$ (all from Invitrogen) was prepared with the dilution buffer described previously and incubated for 45 minutes at room temperature before being washed three times for five minutes in PBS and counterstained with DAPI for three minutes. The sections were mounted with Hydromount (Fisher Scientific), visualised with a light microscope (Olympus IX51) and analyses performed with Cell $\wedge \mathrm{F}$ software. Negative controls were performed throughout using isotype matched Igs instead of primary antibodies.

\section{Results}

LYVE-1 positive infiltrate cells were observed in each of the RA tissue samples tested. A number of them are shown in Figure 1(a). They were scattered throughout the tissue sections showing no specific localisation with LYVE-1 positive lymphatic vessels.

RA Tissue samples were double labelled with LYVE-1 and CD68 and in each case co-localisation of the two markers was observed throughout the tissue (Figures 1(c)-(g)). Negative controls showed no background staining

Minimal LYVE-1 positive infiltrates were also observed in non-RA control tissue (Figure 1(i)). Where present, these infiltrates were weakly stained and sparsely distributed compared to the RA tissue.

\section{Discussion}

Macrophages are well known pro-angiogenic cells which not only release a range of pro-angiogenic molecules but also undergo "transdifferentiation" into blood endothelial cell (BEC) progenitors [9]. Monocytic/macrophage lineage cells have also been identified as the primary source of LECPs [10] and the presence of LECPs has been noted in a wide range of tumours where they play a role in tumour lymphangiogenesis [11]. Further to this, various studies now exist which show associations between macrophage populations and lymphatic vessel density and so support a role for macrophages as lymphangiogenic factors in cancers [12]. Furthermore, associations between CD68+ macrophage populations and metastatic lymph node cancers have also been observed [13]. Experiments to establish the localisation of transplanted LECPs have shown that they are rapidly integrated into lymphatic vessels [11] but that there is a low incorporation frequency of them into new vessels of between $2 \%$ $5 \%$ [14], although one peritonitis model study reported a 50\% incorporation of LECPs [15]. However, some of these studies have also shown that LECPs may be play a vital role in both the initiation of vessel formation and the maintenance of these vessels as they are present for a minimum of six months in the tissue under investigation [16]. In RA, lymphangiogenesis decreases as the disease progresses. This may greatly exacerbate the 


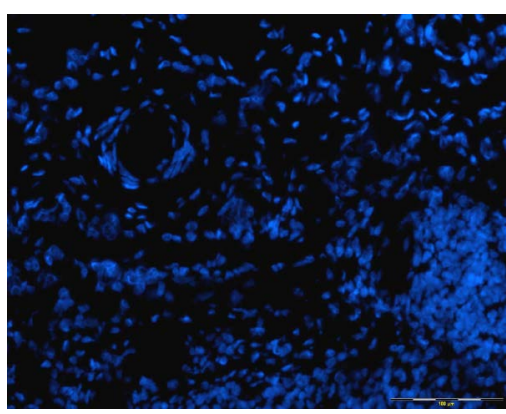

(a)

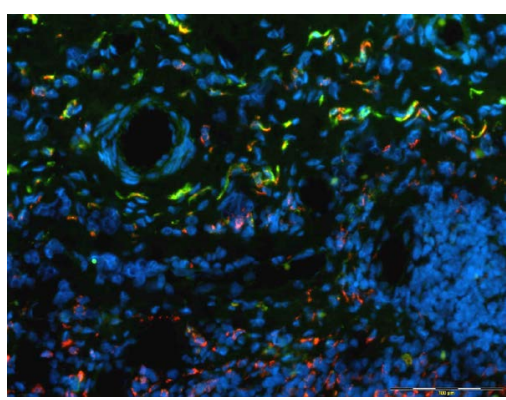

(d)

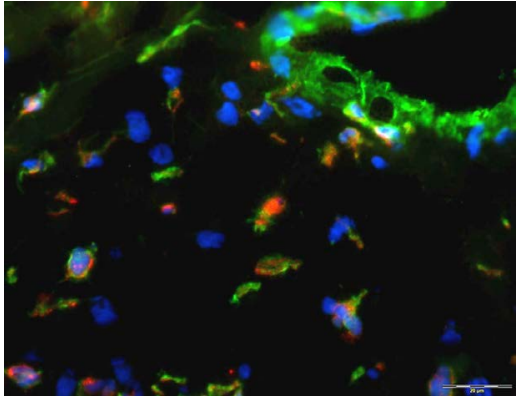

(g)

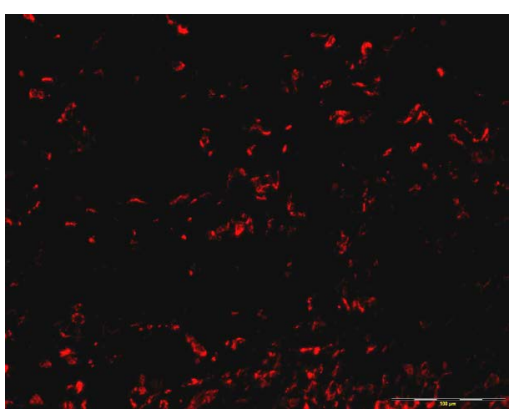

(b)

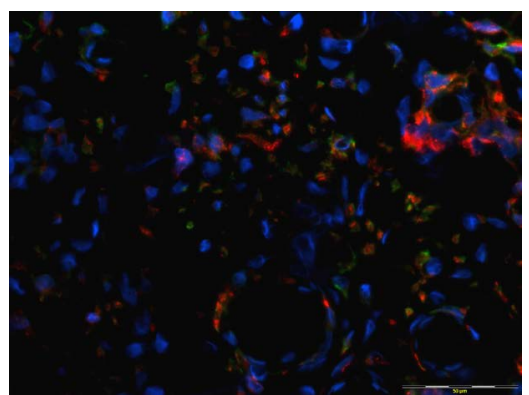

(e)

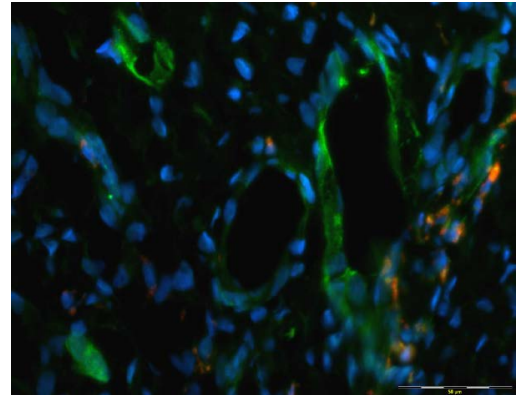

(h)

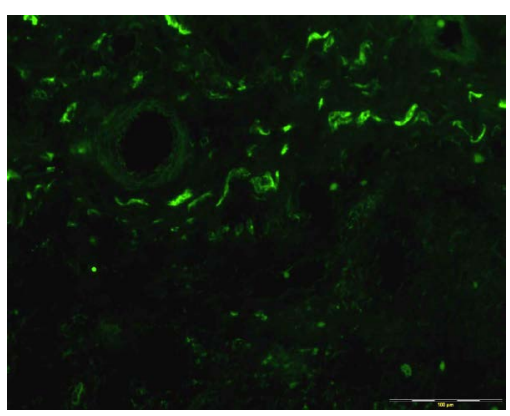

(c)

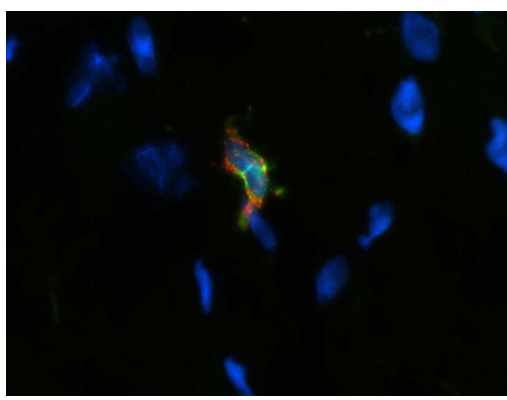

(f)

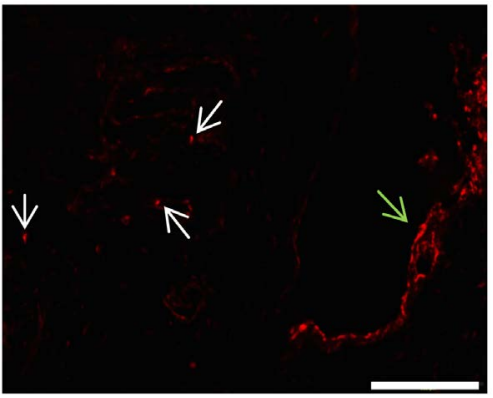

(i)

Figure 1. This figure shows the staining for a number of the RA tissue samples used: (a) shows DAPI (blue), (b) LYVE-1 (red), (c) CD68 (green) and (d) the merged image for RA patient 2. Scale bars: $100 \mu \mathrm{m}$; (e) shows the merged close up image for RA patient 1 . Scale bars: $100 \mu \mathrm{m}$; (f) shows the shows merged image for RA patient 4. Scale bar: $100 \mu$ m; (g) shows the merged image for RA patient 5. Scale bar: $50 \mu \mathrm{m}$; (h) shows the merged image for RA patient 8 . Scale bar: $50 \mu \mathrm{m}$; (i) shows typical staining for non-RA (patient 1 used as example) with a green arrow indicating a lymphatic vessel wall and white arrows indicating examples of weakly LYVE-1 positive infiltrate. Scale bar: $100 \mu \mathrm{m}$. Blue indicates DAPI, red indicates LYVE-1 and green indicates CD68 throughout.

persistence of inflammatory cells. The observations in this study indicate that despite the reduction in lymphangiogenesis at the end stage of the disease, there may be potential for lymphatic vessel development via these LYVE-1 lymphatic progenitors. However, the lack of lymphangiogenesis in late stage RA indicates that these progenitors may not be organised into the physical formation of new lymphatic vessels, nor contribute to pre-existing lymphatic vessels. Further studies are required to explore their role in RA and their potential to augment the lymphatic vasculature.

\section{Acknowledgements}

Thanks go to the Oswestry Rheumatology Association for providing funding for this project.

\section{References}

[1] Schledzewski, K., Falkowski, M., Moldenhauer, G., Metharom, P., Kzhyshkowska, J., Ganss, R., et al. (2006) Lym- 
phatic Endothelium-Specific Hyaluronan Receptor LYVE-1 Is Expressed by Stabilin-1+, F4/80+, CD11b+ Macrophages in Malignant Tumours and Wound Healing Tissue in Vivo and in Bone Marrow Cultures in Vitro: Implications for the Assessment of Lymphangiogenesis. The Journal of Pathology, 209, 67-77. http://dx.doi.org/10.1002/path.1942

[2] Religa, P., Cao, R., Bjorndahl, M., Zhou, Z., Zhu, Z. and Zao, Y. (2005) Presence of Bone Marrow-Derived Circulating Progenitor Endothelial Cells in the Newly Formed Lymphatic Vessels. Blood, 106, 4184-4190. http://dx.doi.org/10.1182/blood-2005-01-0226

[3] Zhang, Q., Lu, Y., Proulx, S.T., Guo, R., Yao, Z., Schwarz, E.M., et al. (2007) Increased Lymphangiogenesis in Joints of Mice with Inflammatory Arthritis. Arthritis Research \& Therapy, 9, R118. http://dx.doi.org/10.1186/ar2326

[4] Xu, H., Edwards, J., Banerji, S., Prevo, R., Jackson, D.G. and Athanasou, N.A. (2003) Distribution of Lymphatic Vessels in Normal and Arthritic Human Synovial Tissues. Annals of the Rheumatic Diseases, 62, 1227-1229. http://dx.doi.org/10.1136/ard.2003.005876

[5] Olszewski, W.L., Pazdur, J., Kubasiewicz, E., Zaleska, M., Cooke, C.J. and Miller, N.E. (2001) Lymph Draining from Foot Joints in Rheumatoid Arthritis Provides Insight into Local Cytokine and Chemokine Production and Transport to Lymph Nodes. Arthritis \& Rheumatology, 44, 541-549. http://dx.doi.org/10.1002/1529-0131(200103)44:3<541::AID-ANR102>3.0.CO;2-6

[6] Zhou, Q., Wood, R., Schwarz, E.M., Wang, Y.J. and Xing, L. (2010) Near-Infrared Lymphatic Imaging Demonstrates the Dynamics of Lymph Flow and Lymphangiogenesis during the Acute versus Chronic Phases of Arthritis in Mice. Arthritis \& Rheumatology, 62, 1881-1889.

[7] Polzer, K., Baeten, D., Soleiman, A., Distler, J., Gerlag, D.M., Tak, P.P., et al. (2008) Tumour Necrosis Factor Blockade Increases Lymphangiogenesis in Murine and Human Arthritic Joints. Annals of the Rheumatic Diseases, 67, 16101616. http://dx.doi.org/10.1136/ard.2007.083394

[8] Whittall, C., Kehoe, O., King, S., Rot, A., Patterson, A. and Middleton, J. (2013) A Chemokine Self-Presentation Mechanism Involving Formation of Endothelial Surface Microstructures. The Journal of Immunology, 190, 1725-1736. http://dx.doi.org/10.4049/jimmunol.1200867

[9] Patenaude, A., Parker, J. and Karsan, A. (2010) Involvement of Endothelial Progenitor Cells in Tumor Vascularization. Microvascular Research, 79, 217-223. http://dx.doi.org/10.1016/j.mvr.2010.01.007

[10] Lee, J.Y., Park, C., Cho, Y.P., Lee, E., Kim, H., Kim, P., et al. (2010) Podoplanin-Expressing Cells Derived from Bone Marrow Play a Crucial Role in Postnatal Lymphatic Neovascularization. Circulation, 122, 1413-1425. http://dx.doi.org/10.1161/CIRCULATIONAHA.110.941468

[11] Ran, S. and Montgomery, K.E. (2012) Macrophage-Mediated Lymphangiogenesis: The Emerging Role of Macrophages as Lymphatic Endothelial Progenitors. Cancers (Basel), 4, 618-657. http://dx.doi.org/10.3390/cancers4030618

[12] Storr, S.J., Safuan, S., Mitra, A., Elliott, F., Walker, C., Vasko, M.J., et al. (2011) Objective Assessment of Blood and Lymphatic Vessel Invasion and Association with Macrophage Infiltration in Cutaneous Melanoma. Modern Pathology, 25, 493-504. http://dx.doi.org/10.1038/modpathol.2011.182

[13] Kurahara, H., Shinchi, H., Mataki, Y., Maemura, K., Noma, H., Kubo, F., et al. (2011) Significance of M2-Polarized Tumor-Associated Macrophage in Pancreatic Cancer. Journal of Surgical Research, 167, e211-e219. http://dx.doi.org/10.1016/j.jss.2009.05.026

[14] Kerjaschki, D., Huttary, N., Raab, I., Regele, H., Bojarski-Nagy, K., Bartel, G., et al. (2006) Lymphatic Endothelial Progenitor Cells Contribute to De Novo Lymphangiogenesis in Human Renal Transplants. Nature Medicine, 12, 230 234. http://dx.doi.org/10.1038/nm1340

[15] Hall, K.L., Volk-Draper, L.D., Flister, M.J. and Ran, S. (2012) New Model of Macrophage Acquisition of the Lymphatic Endothelial Phenotype. PLoS ONE, 7, e31794. http://dx.doi.org/10.1371/journal.pone.0031794

[16] Zumsteg, A., Baeriswyl, V., Imaizumi, N., Schwendener, R., Ruegg, C. and Christofori, G. (2009) Myeloid Cells Contribute to Tumor Lymphangiogenesis. PLOS ONE, 4, e7067. http://dx.doi.org/10.1371/journal.pone.0007067 


\section{Submit or recommend next manuscript to SCIRP and we will provide best service for you:}

Accepting pre-submission inquiries through Email, Facebook, LinkedIn, Twitter, etc.

A wide selection of journals (inclusive of 9 subjects, more than 200 journals)

Providing 24-hour high-quality service

User-friendly online submission system

Fair and swift peer-review system

Efficient typesetting and proofreading procedure

Display of the result of downloads and visits, as well as the number of cited articles

Maximum dissemination of your research work

Submit your manuscript at: http://papersubmission.scirp.org/ 